\title{
Web-Based Decision Support System for Broodstock Management of Siganus guttatus (Bloch, 1787) in Open Fish Cage
}

\author{
Mary Jane Magno-Tan, Axl C. Alejandrino, Conrad G. Dela Cruz, Arnold C. Inoc, and Armin S. \\ Coronado
}

\begin{abstract}
This paper presents a Decision Support System (DSS) for broodstock management of Siganus guttatus - a high valued herbivorous fish species cultured in the Philippines which has a promising commercial potential. The DSS helps aquaculture experts and farmers in monitoring water quality of the fish cages of the breeders known as broodstock. The system predicts future water quality values based on the past and current values; models present and future water quality parameters through graphs; recommends tasks on broodstock management based on the current water quality and provides an early warning for possible fish kill occurrence based on predicted water quality. The algorithm used for the forecasting module of the DSS is Artificial Neural Network (ANN); forecast error was computed by comparing actual and predicted values, to measure the forecast accuracy; and Test-Retest method was used to assess the reliability of the system. The accuracy rate of the system in predicting future water temperature, salinity, and dissolved oxygen are $91.05 \%, 92.67 \%$ and $72.58 \%$ respectively. The forecast accuracy for dissolved oxygen is significantly lower than the forecast accuracy for temperature and salinity because of insufficient training data for dissolved oxygen. The overall accuracy of the system in prediction is $\mathbf{8 5 . 4 4 \%}$. The test-retest reliability of the water quality shows consistency between values for each water parameter, hence the system prediction is considered reliable.
\end{abstract}

Index Terms-Artificial neural networks, decision support system, Siganus guttatus broodstock management, water quality prediction.

\section{INTRODUCTION}

In Philippines and other tropical regions, Siganus guttatus, locally known as Siganid, is one of the major species being cultured since it has a promising commercial potential and because of its herbivorous nature that makes it more environmental friendly than carnivorous fishes [1]. Aside

Manuscript received September 30, 2017; revised November 19, 2017. This work was supported in part by the Polytechnic University of the Philippines and the Philippine's Bureau of Fisheries and Aquatic Resources Region 1 Maritime TechnoDemo Center.

Mary Jane Magno-Tan is with the College of Computer and Information Sicences of the Polytechnic University of the Philippines Sta. Mesa, Manila Philippines (e-mail: mjmtan@pup.edu.ph).

Armin S. Coronado is with Institute for Science and Technology Research of the Polytechnic University of the Philippines Sta. Mesa, Manila Philippines (e-mail: mjmtan@pup.edu.ph).

Axl C. Alejandrino, Conrad G. Dela Cruz, Arnold C. Inoc are with the Polytechnic University of the Philippines Sta. Mesa, Manila Philippines under the College of Computer and Information Sciences, Philippines (e-mail: Axl.alejandrino@gmail.com, epiconrad@gmail.com, iarnoldinoc@gmail.com). from being an excellent food, Siganids are used as baits for tuna and as agents to check algal growth in tropical oyster culture. Regardless of the technology and type of culture system used, the process of cultivation of S.guttatus needs proper handling and management. The life cycle of a typical S. gutattus culture involves conditioning as part of broodstock management and development, which is essential to the hatchery operation process. Broodstock is a group of sexually mature individuals of a cultured species that is kept separate for breeding purposes. In broodstock management, the fishes or breeders are conditioned outdoor in open fish cages until ready for breeding.

Broodstock nutrition directly influences the nutritional reserves of the egg and newly hatched larvae. As pointed out in [2], the nutrition of the breeders is a major factor that affects the production of $S$. guttatus. So, a system that can assist farmers in the everyday management of broodstock is essential for good fish production [3]. Aquaculture production contributes significantly to food security, employment and economy. Unsustainable aquaculture practices can cause ecological and socio-economic problems [4]. When water quality is not monitored for abnormal levels of dissolved oxygen or temperature, fish in cages suffer from unexpected death.

Fish kill is a sudden and significant mortality of fish species. The definition of whether a kill has occurred and its severity can vary greatly according to the situation and who reports it. According to experts in the Philippine's Bureau of Fisheries and Aquatic Resources (BFAR), a fish kill occurrence can be considered if the mortality is $80 \%-100 \%$ of the total population of the fish species. In the Philippines, several fish kill incidents recently occurred involving Laguna Lake, Sampaloc Lake, and the sea waters of Pangasinan, affecting the local aquaculture industry. In 2011, a fish kill in Pangasinan ocurred, where 45 to 70 metric tons of milkfish in fish pens died due to serious depletion of dissolved oxygen in water caused by the occurrence of a neap tide [5]. Low levels of water quality parameter like dissolved oxygen (D.O.) results to algal bloom, which largely contribute to the occurrence of fish kill. The early detection of such occurrence could have prevented huge damage; proper risk mitigation activities would have been implemented.

In [6], the statistical models based on artificial neural networks (ANNs) have been found to be highly suited in forecasting water quality. Various applications for the management of water supply and predicting water quality have been developed but only few are suited for sea-water. In 
[7], artificial neural networks (ANNs) created for freshwater fish caught in Turkey between the years 2003 to 2012 was evaluated; it was concluded that as a decision system, ANNs are important tools for forecast in the area of fisheries.

Likewise, this study utilizes ANN to develop a web-based decision support system (DSS) for aquatic farmers and experts in cultivation of Siganus guttatus in Philippine salt waters. The research is focused on broodstock management of fish in open cages because water quality condition in open cages is hard to maintain since it is directly affected by natural factors like climate change. The DSS assists in remote monitoring of water quality for broodstock management. Web-based DSS is defined as a system that delivers decision support information or tools to a manager or business analyst using a web browser [8]. A web-based system can be accessed by anyone with internet connection. Hence, an aquatic farmer can view the most recent and future water quality status of the broodstock even away from the site and he will be warned if the parameters are not maintained. These information will aid him in making further decisions. The DSS can help in maintaining optimum water quality parameters and thus aid in the prevention of parasites that threaten the fishes in the cage; it also aids in the prevention of mass mortality or fish kill caused by environmental factors, which directly affect the water quality in the cages. The system captures water quality parameters such as temperature, salinity, and dissolved oxygen (D.O.); models the current water quality status, predicts and models the future water quality parameters; and gives a warning on possible occurrence of fish kill based on predicted water quality.

\section{Methodology}

\section{A. Data Source}

The researchers worked with the experts in the Philippine's Bureau of Fisheries and Aquatic Resources - Regional Mariculture Techno-Demo Center (Region I), to obtain historical and current data on water quality, and broodstock management procedures concerning Siganids. They gathered data on the daily record of water salinity, dissolved oxygen, and temperature of a $5 \times 5$ open fish cage which has 150 pcs. of S.guttatus. There are 2-month amount of historical data for dissolved oxygen, while the temperature and salinity has 10 to 11 - month amount of data; these historical data are used as training datasets that the ANN algorithm will learn and use in the prediction.

\section{B. Software Development}

In developing the software, HTML and CSS were used for user interfaces while Python, PHP, JavaScript and Pandas python library were used for generating the reports and graphical models.

\section{System Architecture}

Fig. 1 shows the system architecture which details the flow of the system from input to output.

The current water quality parameters such as water temperature $\left({ }^{\circ} \mathrm{C}\right)$, salinity (ppt), and dissolved oxygen (ppm) are the input to the system. The input data passes through the inference engine where all backend processes of the DSS happens. To interpret the data, the input data are compared and assessed using the historical database - the data set of past water quality, rules for water parameters which need to be maintained, and the facts or data set of the water parameters. Using ANN algorithm, the system forecasts the water quality in the next 31 days based on the input; and models the output thru graphs and reports. The system recommends task/action for broodstock management based on the predicted water quality parameters; it also provides warning on possible fish kill occurrence based on current water quality and historical data.

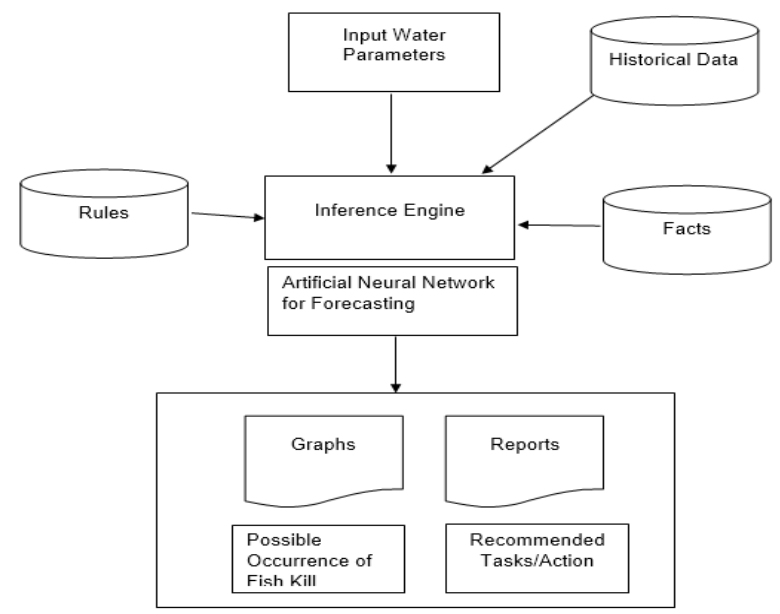

Fig. 1. System architecture.

\section{Data Analysis}

The researchers measured the accuracy of the system in predicting water quality and in recommending tasks, by using Forecast Error Measure. To assess the accuracy of the system in predicting future water quality parameters such as temperature, salinity and dissolved oxygen(D.O.), the actual values were compared to predicted values by the system, to get the absolute percentage error. To measure the accuracy of the system in giving recommended tasks for broodstock management, the expert's assessment for the water quality and the corresponding tasks/actions was compared to the system's assessment and recommended tasks.

To assess the reliability of the system in predicting water quality parameters, the researchers performed Test-Retest Method, which is used to assess the reliability or consistency of a measure from one time to another, to compare the predicted values of temperature, salinity and dissolved oxygen over time. Test-retest was performed by measuring each forecasted water parameter in twelve (12) trials with three (3) replicates; values are compared for consistency.

\section{RESULTS AND DISCUSSION}

\section{A. Measurement of Accuracy in Predicting Water Quality Parameter}

Fig 2 shows the comparison between the actual and predicted values for water temperature.

In Fig. 2, the blue line which represents actual water temperature for 31 days, although not a straight line, has 
almost no fluctuation implying very little variations on the recorded values of temperature over the 31-day period. The red line which represents the forecasted temperature for 31 days has more fluctuations, implying that values are varying over the 31-day period. However, the two lines overlap signifying that there is very little difference in the daily temperature values for the actual and forecast.

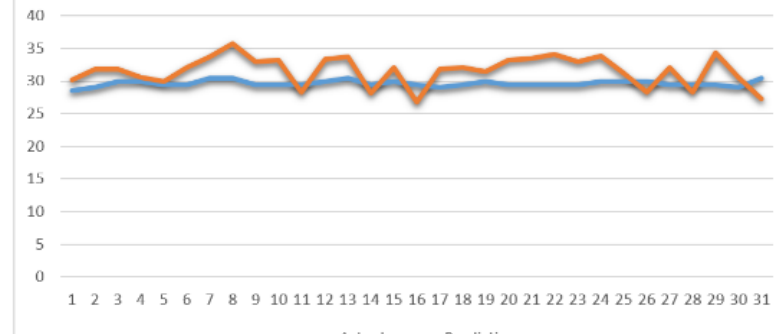

Fig. 2. Actual vs. predicted water temperature in 31 days.

Fig. 3 shows the comparison between the actual and predicted values for salinity.

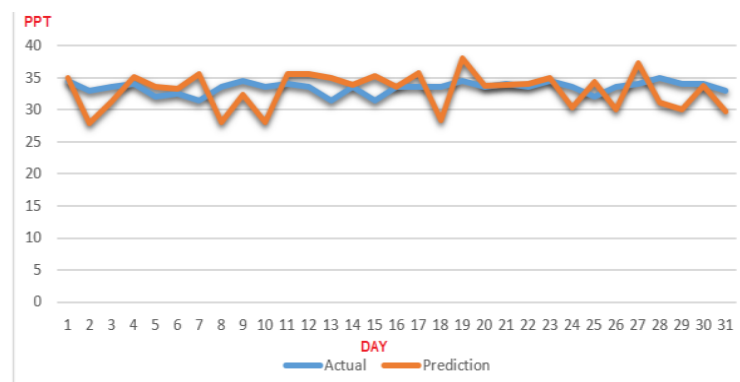

Fig. 3. Actual vs. predicted water salinity in 31 days.

In Fig. 3, the blue line which represent the actual water salinity for 31 days, has very little fluctuations also implying little variations on the recorded values of salinity over the 31-day period. The red line which represents the forecasted salinity for 31 days, has more fluctuations, implying that the salinity values are varying over the 31-day period. However, the two lines overlap signifying that there is very little difference in the daily salinity values for the actual and forecast.

Fig. 4 shows the comparison between the actual and predicted values for dissolved oxygen.

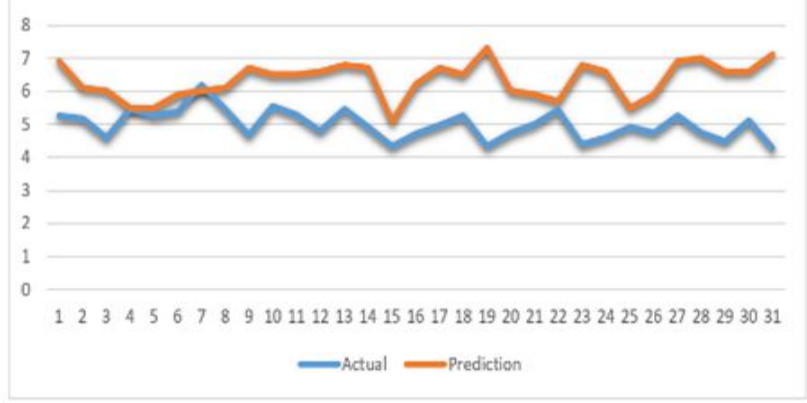

Fig. 4. Actual vs. predicted water D.O. in 31 days.

In Fig. 4, the blue line which represents the actual water D.O. for 31 days has fluctuations, implying variations in D.O. values over the 31-day period. The red line which represents the forecasted D.O. for 31 days, also has fluctuations, implying variations in D.O. values over the 31-day period.
Although the red line representing the forecasted D.O. values, is slightly above the blue line representing the actual D.O. values, which means the values for the forecasted D.O. are a bit higher than the actual D.O., both lines have trends that are similar to each other. It means that the forecast on whether the D.O. value will go up or go down is the same with the rise and fall of the actual D.O. values.

Table I shows the result of the test conducted to measure the accuracy of the system in predicting future water temperature, salinity and dissolved oxygen.

TABLE I: Result OF THE TEST FOR MEASURING THE ACCURACY OF THE DSS IN PREDICTING FutURE WATER QUALITY

\begin{tabular}{|c|c|c|c|c|c|c|c|c|c|}
\hline \multirow[t]{2}{*}{ DAY } & \multicolumn{3}{|c|}{ TEXVERATURE (C) } & \multicolumn{3}{|c|}{ SALNITY (CD) } & \multicolumn{3}{|c|}{ DISSOLVED OXYGEN } \\
\hline & Actual & $\begin{array}{c}\text { Predictio } \\
\text { a }\end{array}$ & $\begin{array}{l}\text { Absolute } \\
\text { Percenta } \\
\text { ge Error } \\
\text { (APE) }\end{array}$ & Actual & $\begin{array}{l}\text { Predi } \\
\text { ction }\end{array}$ & APE & Actual & $\begin{array}{l}\text { Predi } \\
\text { ction }\end{array}$ & APE \\
\hline 1 & 28.5 & 30.2 & 0.05965 & 34.5 & 34.9 & 0.01043 & 5.25 & 6.9 & 0.30285 \\
\hline 2 & 29 & 31.8 & 0.09655 & 33 & 27.9 & 0.15545 & 5.165 & 6.1 & 0.18059 \\
\hline 3 & 30 & 31.9 & 06333 & 33.5 & 31.3 & 0.06597 & 4.58 & 6 & 0.29732 \\
\hline 4 & 30 & 30.6 & 0.02 & 34 & 35.1 & 0.03203 & 5.47 & 5.5 & 0.00341 \\
\hline 5 & 29.5 & 30 & 0.01695 & 32 & 33.6 & & 5.25 & 5.5 & 0.04186 \\
\hline 6 & 29.5 & 32.1 & 0.08814 & 32.5 & 33.3 & 0.02362 & 5.37 & 5.9 & 0.08918 \\
\hline 7 & 30.5 & 33.7 & 10492 & 31.5 & 35.6 & 0.12961 & 6.185 & 6 & 0.0367 \\
\hline$s$ & 30.5 & 35.7 & 0.17049 & 33.5 & 28.1 & 0.1637 & 5.46 & 6.1 & 0.11412 \\
\hline 9 & & 33 & & 34.5 & 32.3 & & 4.685 & & \\
\hline 10 & 29.5 & 33.2 & 0.12542 & 33.5 & 28 & 0.16422 & 5.535 & 6.5 & 0.16643 \\
\hline 11 & 29.5 & & 04068 & 34 & 35.5 & 0.04294 & 5.29 & 6.5 & 0.21316 \\
\hline 12 & & & 0.11 & 33.5 & 35.6 & 0.06121 & 4.79 & 6.6 & 0.37474 \\
\hline 13 & 30.5 & 33.7 & 0.10492 & 31.5 & 35 & 0.1091 & 5.455 & 6.8 & 0.24483 \\
\hline 14 & 29.5 & & 04407 & 33.5 & 33.9 & 0.01124 & 4.915 & 6.7 & 0.34657 \\
\hline 15 & & & & & & & 4.32 & & 0.17865 \\
\hline 16 & 29.5 & & 0.091 & & & & 4.72 & & 0.31047 \\
\hline 17 & 29 & 31.8 & 99655 & 33.5 & 35.8 & 0.06769 & 4.965 & 6.7 & 0.34832 \\
\hline is & 29. & & 4 & .5 & 28.3 & 0.15 & 5.25 & 6.5 & 0.23167 \\
\hline 19 & & & & & 38 & & & 7.3 & \\
\hline 20 & 29 & 33.2 & 20 & 33.5 & 33.8 & & 4.75 & 6 & 0.25906 \\
\hline 21 & 29.5 & 33.5 & & 34 & 33.9 & 0.00 & 5.01 & 5.9 & 0.17041 \\
\hline 22 & & & & 33.5 & & & 5.435 & 7 & 0.04669 \\
\hline 23 & 29.5 & 33 & & & & 0. & 4.395 & 6.8 & 0.53732 \\
\hline 24 & 30 & 33.8 & 0.12667 & 33.5 & 30.3 & 0.09824 & 4.6 & 6.6 & 0.43157 \\
\hline 25 & 30 & & & 32 & & & 4.925 & 5.5 & 0.11049 \\
\hline 26 & & & 7 & 33.5 & & & 4.7. & 5.9 & 0.226 \\
\hline 27 & 29.5 & 32.1 & 0.08814 & 34 & 37.2 & 0.09321 & 5.265 & 6.9 & 0.29527 \\
\hline 28 & 29.5 & & & 35 & 31.1 & & & 7 & \\
\hline 29 & 29.5 & & & 34 & 30 & & & 6.6 & \\
\hline 30 & 29 & 30.6 & 0.05517 & 34 & 33.8 & 0.00697 & 5.115 & 6.6 & 0.28063 \\
\hline \multirow{2}{*}{\multicolumn{2}{|c|}{$31{ }_{\text {TAPE }}^{30.5}$}} & 27.3 & 0.10492 & 33 & 29.8 & 0.09767 & 4.265 & 7.1 & 0.64222 \\
\hline & & & 2.77391 & & & 2.26947 & & & 8.50034 \\
\hline \multirow{2}{*}{\multicolumn{2}{|c|}{$\begin{array}{l}\text { orecast Erro } \\
\text { Accuracy }\end{array}$}} & & 8.94808 & & & 7.32087 & & & 27.4205 \\
\hline & & & 91.0519 & & & 92.6791 & & & 72.5795 \\
\hline & & & Overall & 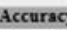 & & & & & 85.44 \\
\hline
\end{tabular}

In Table I, the actual and predicted values of the water temperature, salinity and dissolved oxygen were tabulated. Absolute percentage error of the forecast was calculated using the formula

$$
\frac{\left|A_{n}-F_{n}\right|}{\left|A_{n}\right|}
$$

in order to compute the Forecast Error using the formula:

$$
\frac{1}{n} \sum_{t=1}^{n} \frac{\left|A_{t}-F_{t}\right|}{\left|A_{t}\right|} \times 100
$$

where $A$ is Actual Value and $F$ is the forecast value and the Forecast Accuracy ( $\mathrm{FA}=100 \%$ - FE). The computed accuracy rate for temperature, salinity and D.O. is $91.05 \%$, $92.67 \%$ and $72.58 \%$ respectively. Although the accuracy of the system in predicting D.O. is lower than in the prediction of temperature and salinity, the average and overall accuracy for water quality prediction remains high at a rate of $85.44 \%$.

\section{B. Measurement of Accuracy in Recommending Action}

Table II shows the comparison of the expert's recommended action and the recommended action by the DSS based on the values of temperature, salinity, and dissolved oxygen. 
TABLE II: RESUlT OF THE TEST FOR MEASURING THE ACCURACY OF THE DSS IN GIVING RECOMMENDED TASKS/ACTION

\begin{tabular}{|c|c|c|c|c|c|c|c|c|}
\hline \multirow[t]{2}{*}{ DAY } & \multicolumn{2}{|c|}{ Temperature } & \multicolumn{2}{|c|}{ Solinity } & \multicolumn{2}{|c|}{$\begin{array}{l}\text { Dissolved } \\
\text { Oxygen }\end{array}$} & \multicolumn{2}{|c|}{ Recommended Taska/Action } \\
\hline & Actual & $\begin{array}{c}\text { Predictio } \\
\text { n }\end{array}$ & Actual & $\begin{array}{l}\text { Predi } \\
\text { ction }\end{array}$ & Actual & $\begin{array}{l}\text { Predi } \\
\text { ction }\end{array}$ & DSS & Expert \\
\hline 1 & 28.5 & 30.2 & 34.5 & 34.9 & 5.25 & 6.9 & $\begin{array}{l}\text { nfa (no further } \\
\text { action) }\end{array}$ & nfa \\
\hline 2 & 29 & 31.8 & 33 & 27.9 & 5.165 & 6.1 & nfa & nfa \\
\hline 3 & 30 & 31.9 & 33.5 & 31.3 & 4.58 & 6 & nfa & nfa \\
\hline 4 & 30 & 30.6 & 34 & 35.1 & 5.47 & 5.5 & nfa & nfa \\
\hline 5 & 29.5 & 30 & 32 & 33.6 & 5.25 & 5.5 & nfa & nfa \\
\hline 6 & 29.5 & 32.1 & 32.5 & 33.3 & 5.37 & 5.9 & nfa & nfa \\
\hline 7 & 30.5 & 33.7 & 31.5 & 35.6 & 6.185 & 6 & nfa & nfa \\
\hline 8 & 30.5 & 35.7 & 33.5 & 28.1 & 5.46 & 6.1 & nfa & nfa \\
\hline 9 & 29.5 & 33 & 34.5 & 32.3 & 4.685 & 6.7 & nfa & nfa \\
\hline 10 & 29.5 & 33.2 & 33.5 & 28 & 5.535 & 6.5 & nfa & nfa \\
\hline 11 & 29.5 & 28.3 & 34 & 35.5 & 5.29 & 6.5 & nfa & nfa \\
\hline 12 & 30 & 33.3 & 33.5 & 35.6 & 4.79 & 6.6 & nfa & nfa \\
\hline 13 & 30.5 & 33.7 & 31.5 & 35 & 5.455 & 6.8 & nfa & nfa \\
\hline 14 & 29.5 & 28.2 & 33.5 & 33.9 & 4.915 & 6.7 & nfa & nfa \\
\hline 15 & 30 & 32.1 & 31.5 & 35.2 & 4.32 & 5.1 & nfa & nfa \\
\hline 16 & 29.5 & 26.8 & 33.5 & 33.6 & 4.72 & 6.2 & nfa & nfa \\
\hline 17 & 29 & 31.8 & 33.5 & 35.8 & 4.965 & 6.7 & nfa & nfa \\
\hline 18 & 29.5 & 32.1 & 33.5 & 28.3 & 5.25 & 6.5 & nfa & nfa \\
\hline 19 & 30 & 31.5 & 34.5 & 38 & 4.32 & 7.3 & nfa & $\begin{array}{l}\text { freshwater } \\
\text { bath }\end{array}$ \\
\hline 20 & 29.5 & 33.2 & 33.5 & 33.8 & 4.75 & 6 & nfa & nfa \\
\hline 21 & 29.5 & 33.5 & 34 & 33.9 & 5.01 & 5.9 & nfa & nfa \\
\hline 22 & 29.5 & 34.1 & 33.5 & 34.1 & 5.435 & 5.7 & nfa & nfa \\
\hline 23 & 29.5 & 33 & 34.5 & 34.9 & 4.395 & 6.8 & nfa & nfa \\
\hline 24 & 30 & 33.8 & 33.5 & 30.3 & 4.6 & 6.6 & nfa & nfa \\
\hline 25 & 30 & 31.2 & 32 & 34.4 & 4.925 & 5.5 & nfa & nfa \\
\hline 26 & 30 & 28.3 & 33.5 & 30.1 & 4.745 & 5.9 & nfa & nfa \\
\hline 27 & 29.5 & 32.1 & 34 & 37.2 & 5.265 & 6.9 & nfa & $\begin{array}{l}\text { freshwater } \\
\text { bath }\end{array}$ \\
\hline 28 & 29.5 & 28.3 & 35 & 31.1 & 4.745 & 7 & nfa & nfa \\
\hline 29 & 29.5 & 34.4 & 34 & 30 & 4.465 & 6.6 & nfa & nfa \\
\hline 30 & 29 & 30.6 & 34 & 33.8 & 5.115 & 6.6 & nfa & nfa \\
\hline 31 & 30.5 & 27.3 & 33 & 29.8 & 4.265 & 7.1 & nfa & nfa \\
\hline \multicolumn{7}{|c|}{ Forecast Error } & \multicolumn{2}{|c|}{6.4516} \\
\hline & & & uracy & & & & 93.5 & \\
\hline
\end{tabular}

In Table II, the expert's advice and the recommended action of the DSS are compared; and accuracy rate of the decision support system in recommending actions is computed as $93.54 \%$.

\section{Measurement of Reliability in Predicting Water Quality Parameters}

Table III shows the result of the test-retest for predicted temperature, salinity and dissolved oxygen, to measure the system's reliability in forecasting future water quality parameters.

TABLE III: TEST-RETEST RELIABILITY FOR PREDICTING WATER QUALITY PARAMETERS

\begin{tabular}{|c|c|c|c|c|c|c|c|c|c|}
\hline \multirow[b]{2}{*}{ Date } & \multicolumn{3}{|c|}{ Temperature $\left({ }^{\circ} \mathrm{C}\right)$} & \multicolumn{3}{|c|}{ Salinity (ppt) } & \multicolumn{3}{|c|}{ Dissolved Oxygen (ppm) } \\
\hline & Test I & Test II & Test III & Test I & Test II & Test III & Test I & Test II & $\begin{array}{l}\text { Test } \\
\text { III }\end{array}$ \\
\hline $\operatorname{Jan} 1$ & 32.65 & 32.06 & 32.91 & 35.66 & 35.02 & 35.01 & 5.10 & 5.59 & 5.02 \\
\hline Feb 1 & 32.81 & 32.05 & 32.08 & 33.79 & 33.44 & 33.84 & 5.12 & 5.16 & 5.69 \\
\hline Mar 1 & 30.90 & 30.16 & 30.54 & 33.64 & 33 & 33.57 & 4.83 & 4.13 & 4.42 \\
\hline Apr 1 & 32.36 & 32.92 & 32.06 & 34.02 & 34.36 & 34.92 & 5.81 & 5.61 & 5.18 \\
\hline May 1 & 32.46 & 32.47 & 32.46 & 33.27 & 33.50 & 33.43 & 6.10 & 6.24 & 6.21 \\
\hline $\operatorname{Jun} 1$ & 32.49 & 32.79 & 32.81 & 33.94 & 33.55 & 33.44 & 5.96 & 5.89 & 5.36 \\
\hline Jul 1 & 32.15 & 32.15 & 32.18 & 32.39 & 32.38 & 32.43 & 5.79 & 5.71 & 5.64 \\
\hline Aug 1 & 33.20 & 33.26 & 33.21 & 33.44 & 33.56 & 33.03 & 5.37 & 5.53 & 5.81 \\
\hline Sep 1 & 32.01 & 32.05 & 32.08 & 31.69 & 31.78 & 31.95 & 4.74 & 4.79 & 4.69 \\
\hline Oet 1 & 33.71 & 33.77 & 33.77 & 34.74 & 34.42 & 34.04 & 6.35 & 6.46 & 6.27 \\
\hline Nov 1 & 32.53 & 32.60 & 32.69 & 35.97 & 35.30 & 35 & 5.03 & 5.19 & 5.02 \\
\hline Dec 1 & 32.42 & 32.50 & 32.39 & 33.55 & 33.37 & 33.69 & 6.03 & 6.03 & 6.15 \\
\hline
\end{tabular}

The predicted values of each water quality parameter (temperature, salinity, D.O.) are compared for twelve (12) trials in three (3) replicates with one (1) month interval. The result shows consistency between the values.

\section{Accuracy of the DSS in Water Quality Prediction and in Giving Recommended Action}

Table IV shows the summary of the accuracy of the system in predicting water temperature, salinity, dissolved oxygen, as well as in suggesting the recommended tasks.

TABLE IV: SUMMARY OF THE ACCURACY OF THE DSS IN PREDICTING WATER QUALITY AND RECOMMENDING ACTIONS

\begin{tabular}{|l|l|}
\hline Predicted Values & Accuracy Rate (\%) \\
\hline Temperature & 91.05 \\
\hline Salinity & 92.67 \\
\hline Dissolved Oxygen & 72.58 \\
\hline Recommended Tasks & 93.54 \\
\hline
\end{tabular}

In Table IV, the accuracy rate of the system in predicting temperature is high with a rate of $91.05 \%$; the accuracy rate of the system in predicting salinity is high with a rate of $92.67 \%$; the accuracy rate of the system in predicting dissolved oxygen is significantly lower with a rate of $72.58 \%$; the accuracy rate of the system in recommending actions is very high with a rate of $93.54 \%$.

The forecast accuracy for dissolved oxygen is significantly lower than the forecast accuracy of temperature and salinity due to insufficient historical data gathered that are used as training data for the DSS. There is only 2-month amount of training data for dissolved oxygen, while the temperature and salinity has a 10 to 11 - month amount of training data sets. This is due to unavailability of data on dissolved oxygen gathered from the source.

\section{CONCLUSIONS AND RECOMMENDATIONS}

The forecast accuracy of the DSS for water temperature and salinity is significantly higher than the forecast accuracy for dissolved oxygen. The amount of historical data used for training the prediction model affects the forecast accuracy of the DSS. To increase forecast accuracy rate for dissolved oxygen, it is recommended that the number of historical data on D.O. that will be used in training the DSS, be the same as the number of training data on salinity and temperature which should be at least 12 months.

The computed accuracy rate of the DSS in giving recommended tasks or actions for broodstock management is high because the gathered data for temperature, salinity, and dissolved oxygen were mostly optimal values hence most recommended actions were 'no further action'. This assessment may change if the gathered data sets fall below or above the optimal or standard values. To have a more realistic accuracy rate of the system in giving recommended tasks, gather data sets of water parameters (temperature, salinity, and dissolved oxygen) with values that fall above or below optimal or standard values; the standard values for temperature are 28 to $30^{\circ} \mathrm{C}$; the standard values for salinity are 24 to $32 \mathrm{ppt}$; the standard values for dissolved oxygen are 4 to $5 \mathrm{ppm}$.

It is concluded that the ANN algorithm used in the decision support system is accurate in predicting sea water quality 
parameters for broodstock management of $S$. gutattus in open fish cages, and in giving advice or recommended actions to aquatic farmers.

The Test-Retest for reliability shows consistency between values for the water salinity, temperature and dissolved oxygen. This implies that the system is highly reliable in predicting the future quality parameters. The occurrence of fish kill directly depends on the water parameters. If certain parameter is not properly maintained to its optimal value, it will affect the quality of the water and the health of the fishes. Past incidents show causes of mass mortality as due to oxygen depletion, and dissolved oxygen depends on temperature and other water quality factors like water salinity. Fish kill depends on water quality parameters such as temperature, salinity, and dissolved oxygen. If the forecast of future water quality is reliable, it may be implied that the warning on possible occurrence of fish kill is reliable too. However, Barica, N.D. (2015) suggests that collecting parameters pertaining to seasonal fish mortalities should be done in three (3) different but related disciplines - aquaculture, meteorology, and limnology [9]. Hence, the system needs to be tested also in its accuracy in predicting fish kill based on actual historical data on fish kill occurrence concerning $S$. guttatus. Since no available data on fish kill concerning $S$. guttatus can be gathered from the source, it is recommended that cultivators of this high valued species diligently record fish kill incidents concerning the species. These records will serve as historical training data that will be fed into the ANN algorithm to learn data patterns for a more accurate fish kill prediction. Hence, a more accurate measure of reliability in predicting fish kill will be based on the accuracy of predicting fish kill based on actual historical fish kill data or incidents. If no available data on $\mathrm{S}$. guttatus fish kill incident can be gathered, other species of the same characteristics or family may be considered as a training data set. The system can also be extended to handle other species with recorded fish kill incidents (e.g. milkfish), by adding rules on the decisions generated by the system in accordance to the species. Other researchers may consider other water quality parameters as predictors like ammonia, and $\mathrm{pH}$ level; and gather enough training data set for these parameters.

\section{ACKNOWLEDGMENT}

Our thanks to Dir. Nestor Domenden and Ms. Antonietta Evangelista of the Philippine's Bureau of Fisheries and Aquatic Resources (BFAR) Region 1 for the accommodation, technical assistance and for the data used in the research.

\section{REFERENCES}

[1] M. N. Duray and Southeast Asian Fisheries Development Center. (1998). Biology and Culture of Siganids. [Online]. Available: https://repository.seafdec.org.ph/bitstream/handle/10862/535/Siganid s.pdf

[2] J. G. Gorospe and C. G. Demayo, "Population variability of the Golden rabbitfish in northern Mindanao, Philippines," International Journal of the Bioflux Society (AACL Bioflux), vol. 6, no. 3, pp. 188-214, May 2013.

[3] D. A. Davis and M. T. Dinis. (2013). Marine larval fish production: A nutritional perspective. [Online]. Available: http://fisheries.tamu.edu/files/2013/09/Marine-Larval-Fish-Productio n-A-Nutritional-Perspective.pdf
[4] Food and Agriculture Organization of the United Nations, The State of World Fisheries and Aquaculture, 2012.

[5] InteraksyonNews. (2011). [Online]. Available: http://www.interaksyon.com/article/4561/new-fish-kill-in-Pangasinan

[6] G. C. Dandy, R. J. May, H. R. Maier, and J. B. Nixon, "Application of partial mutual information variable selection to ANN forecasting of water quality in water distribution systems," Environmental Modelling \& Software, vol. 23, no. 10-11, pp. 1289-1299, 2008.

[7] Benzer and Benzer, "Application of artificial neural network into the freshwater fish caught in Turkey," International Journal of Fisheries and Aquatic Studies, vol. 2, no. 5, pp. 341-346. 2015.

[8] D. J. Power. (May 31, 2003). A brief history of decision support systems. DSSResources.COM, World Wide Web. [Online]. Available: http://DSSResources.COM/history/dsshistory.html

[9] N. D. Barica, "Nutrient dynamics in eutrophic inland waters used for aquaculture," FAO Corporate Document Repository, 2015.

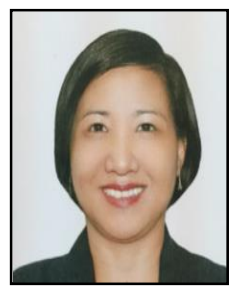

Mary Jane Magno-Tan was born in Olongapo City Philippines on September 17, 1971. She earned her master's degree in information Technology from the Polytechnic University of the Philippines Graduate School in 2005.

She worked as Programmer and later on as Systems Analyst at Applied Ideas, Inc. from 1992 to 1997. She was the chief of the Polytechnic University of the Philippine's Center for Computing and Information Science Research from June 2015 to June 2017. She is currently a full-time assistant professor at the Polytechnic University of the Philippines under the College of Computer and Information Sciences. She has presented and published several research articles in international conferences and journals in information technology and computer science. Her previous research interest is on university and college management information systems while her current research interest is on artificial intelligence and decision support systems

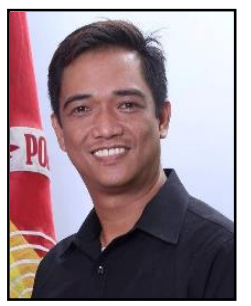

Armin S. Coronado was born in Manila on July 13, 1971. He earned his masters degree in biology from Ateneo de Manila University in 2009. He is currently working on his dissertation for his doctorate degree in botany from the University of the Philippines.

$\mathrm{He}$ was the chairperson of the Polytechnic University of the Philippines' Department of Biology from July 2014 to June 2016; and chief of the university's center for life science research from October 2013 to June 2015 . He is currently an associate professor and director of the Polytechnic University of the Philippines' Institute for Science and Technology Research. He has presented and published several research articles in international conferences and journals in biology. His specialization and current research interest is on phycology.

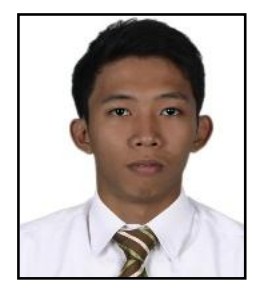

Axl C. Alejandrino was born in Pasig City Philippines on April 23, 1996. He earned his bachelors degree in computer science at the Polytechnic University of the Philippines in 2015.

He now works as a software developer at Amdocs in Taguig City, Philippines.

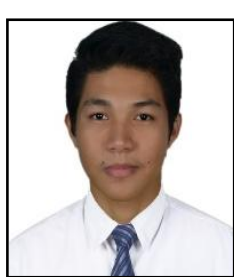

Conrad G. de la Cruz was born in Kawit, Cavite Philippines on August 12, 1995. He earned his bachelor's degree in computer science at the Polytechnic University of the Philippines in 2015.

He now works as a software developer at Amdocs in Taguig City, Philippines.

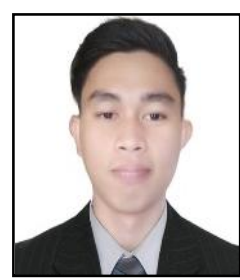

Arnold C. Inoc earned his bachelor's degree in computer science at the Polytechnic University of the Philippines in 2015.

He now works as $\underline{L} 2$ application support at Indra in Pasig City, Philippines. 